and cathepsin B activity in several individual tissues of foetal and senescent rats. Comp Biochem Physiol 1985; 82B: $849-53$.

6 Holt RP, Yeh K-y, Kotler DP. Altered controls of proliferation in small intestine of the senescent rat. Proc Natl Acad Sci USA 1988; 85: 2771-5.

7 Holt PR, Yeh K-y. Colonic proliferation is increased in senescent rats. Gastroenterology 1988; 95: 1556-63.

\section{Low gluten diet for adult coeliac disease}

SIR, - Dr Montgomery and colleagues conclude that adult coeliac patients can tolerate a low gluten diet without developing gross morphological changes in their jejunal mucosa or significant antigluten antibody responses. ${ }^{1}$ These conclusions were based on detailed comparisons of jejunal morphology and serology in groups of patients on low gluten or gluten free diets. In an earlier study from the St Bartholomew's group, 27 of 85 patients with coeliac disease were found to be asymptomatic despite not maintaining a strict gluten free diet. ${ }^{2}$ It would be of interest to know if the 13 low gluten diet patients in the recent study were taken from the 27 that were not maintaining a strict gluten free diet in the first study. If this is the case, I would submit that the low gluten group are a self-selected subset of patients able to maintain good health without adhering to a strict diet, and that it would be premature to conclude that the favourable results in this subset apply to all patients with adult coeliac disease. In order to answer this question, a controlled trial is required randomising unselected patients with coeliac disease in emission to either a low gluten or a strict gluten free diet.

Gartnavel General Hospital,

M C ALLISON

1053 Great Western Road,

Glasgow G12 OYN

\section{References}

1 Montgomery AMP, Goka AKJ, Kumar PJ, Farthing MJG, Clark ML. Low gluten diet in the treatment of adult coeliac disease: effect on jejunal morphology and serum anti-gluten antibodies. Gut 1988; 29: 1564-8.

2 Kumar PJ, Harris G, Colyer J, Clark ML, Dawson AM. Is a gluten free diet necessary for the treatment of coeliac disease? [Abstract]. Gastroenterology 1985; 88: 1459.

\section{Reply}

SIR, - The patients on the low gluten diet in the paper from Gut were not taken from the original study of 85 patients. I would entirely agree with Dr Allison that if this was the case the low gluten group would be self-selected subset of patients. We are currently considering a trial by 'prospectively' putting patients on low gluten diet or maintaining a strict gluten free diet.
St Bartholomew's Hospital,

P J KUMAR

West Smithfield,

London ECIA $7 B E$

Dietary factors in the aetiology of gall stones

SIR, - Drs Pixley and Mann did not find any association between gall stone disease and different nutrients in their study. 'They argue that this lack of association could be that all non-vegetarians eat excessive quantities of saturated fat, animal protein, and refined sugar to allow any differences to be detected. Looking at their frequency histograms, a considerable variation in energy intake and intake of different nutrients is seen - for example, from 0 to $180 \mathrm{~g}$ of refined sugar. If such a range is not sufficient, what is sufficient?

Evaluating the literature of clinical studies gives the impression of considerable disagreement about the relationship between diet and gall stones. Intake of fat ranges from being positively associated, ${ }^{2}$ not associated $^{3}$ and negatively associated ${ }^{4}$ with gall stones. The same is seen for energy intake. Clinical studies do not give us an unequivocal answer that any nutrients should be associated with gall stones. But all the clinical studies concerning this subject share one thing in common: they all use prevalence data on gall stone disease. This means that they compare present diet with gall stones which perhaps have been formed years ago. At that time the diet would not necessarily have been the same as it is today, as change in diet over time can be substantial. ${ }^{5}$ It is questionable whether participants' memory regarding their diet over the last 20-30 years is sufficient to state whether it has changed or not. We, therefore, need data from incidence studies comparing dietary habits in those who form gall stones in the study period as compared with those who do not, before we can make a clinical evaluation as regards the association between diet and gall stone disease.

TORBEN JøRGENSEN

Surgical Dept D,

KAS Herlev,

DK-2730 Herlev,

Denmark

\section{References}

1 Pixley F, Mann J. Dietary factors in the aetiology of gall stones: a case control study. Gut 1988; 29: 1511-5.

2 Scragg RKR, McMichael AJ, Baghurst PA. Diet alcohol and relative weight in gall stone disease.: a case-control study. Br Med J 1984; 288: 1113-9.

3 Sarles H, Gerolami A, Bord A. Diet and cholesterol gallstones. A further study. Digestion 1978; 17: 128-34.

4 Wheeler M, Hills LL, Laby B. Cholelithiasis: a clinical and dietary survey. Gut 1970; 11: 430-7. 
5 Dawber TR, Pearson G, Anderson P, et al. Dietary assessment in the epidemiologic study of coronary heart disease: the Framingham study. Am J Clin Nutr 1962; 11: $226-34$.

\section{Hepatocellular carcinoma in idiopathic haemochromatosis}

SIR, - The recent reports in Gastroenterology ${ }^{1}$ and $G u t^{2}$ of hepatoma developing in the non-cirrhotic liver of patients with treated haemochromatosis prompts us to record the following case:

A 42 year old man presented in 1973 with marked irregular hepatomegaly. A liver biopsy showed cirrhosis and haemochromatosis. Venesection over a four year period resulted in clinical improvement and the liver became normal in size. Tiredness and sexual ability were helped by occasional injections of Nandrolone decanoate.

In 1981 he developed erythromelalgia and a thrombocythaemia of over $10^{12} / 1$. Both responded to intermittent courses of hydroxyurea. Alpha foetoprotein level, ultrasound and isotope liver scans were normal.

In 1987 at the age of 57 he presented with a two month history of fever, rigors and weight loss of 22 $\mathrm{kg}$. Alpha foetoprotein was over $1100 \mu \mathrm{g} / \mathrm{l}$ (normal $<5$ ). Computed tomography scan showed multiple filling defects within the liver. Two liver biopsies showed normal liver tissue without fibrosis or excess iron. Subsequent guided needle aspiration showed hepatoma cells. He did not respond to chemotherapy and died two weeks later. Autopsy was not carried out.

The apparent complete reversal of fibrosis and iron storage in the liver of this patient suggests that some other mechanism may be responsible for the tumour development. It would be interesting to know if anabolic steroids were given to the patients in the other reports.

Perhaps this sequence of events may be more common than hitherto realised because of a reluctance to report single cases.

F SHEEHAN, C E CONNOLLY, AND C F MCCARTHY

Department of Gastroenterology,

Histopathology and Medicine,

Regional Hospital,

University College Galway,

Ireland

\section{References}

1 Blumberg RS, Choppa S, Ibrakim R, et al. Primary hepatocellular carcinoma in idiopathic hacmochromatosis after reversal of cirrhosis. Gastroenterology 1988; 95: $1399-402$.

2 Fellows IW, Steward M, Jeffcoate WJ, et al. Hepatocellular carcinoma in primary hacmochromatosis in the absence of cirrhosis. Gut 1988; 29: 1603-6.
Primary mucinous adenocarcinoma developing in an ileostomy stoma

SIR, - The case report by Smart and colleagues (Gut 1988; 29: 1607-12) highlights a rare but significant complication of a longstanding ileostomy. They have shown that colonic metaplasia has occurred on the ileostomy of their patient, who initially had the colectomy for ulcerative colitis. I have recently reported a case, ' in which colonic metaplasia occurred on the ileostomy stoma of a patient who had had a total colectomy for polyposis coli. The external aspect of the ileostomy was the site of several tubulovillous adenomas, which appeared to arise in areas of colonic metaplasia. This patient had no evidence of polyposis elsewhere in the gastrointestinal tract. Another case report, not mentioned by Smart and colleagues, records colonic type polyps on an ileostomy, with malignant transformation in one of them, in a patient who had a colectomy for familial polyposis."

Colonic metaplasia and adenomatous transformation may also occur within ileostomy reservoirs, either with continent ileostomy or with sphincter saving procedures. ${ }^{3-5}$ The potential for colonic metaplasia, with subsequent neoplasia, is a cause for concern at a time when increasing numbers of patients are being offered ileal pouches. Those who create such pouches must be aware that colonic type tumours may arise in the ileal mucosa. This risk seems to be greatest in patients with familial adenomatous polyposis, but the report by Smart and colleagues shows that there is also a similar risk in patients with ulcerative colitis.

C D JOHNSON

Department of Surgery,

University Surgical Unit,

F Level, Centre Block,

Southampton General Hospital,

Southampton $\mathrm{SOl} 6 \mathrm{HO}$

\section{References}

1 Johnson CD, White $\mathrm{H}$. Colonic metaplasia with colonic type polyps on an ileostomy stoma in polyposis coli; Report of a case. Dis Colon Rectum 1988; 31: 405-7.

2 Primrose JN, Quirke P, Johnston D. Carcinoma of the ileostomy in a patient with familial adenomatous polyposis. Br J Surg 1988; 75: 384.

3 Beart RW. Fleming R, Banks PM. Tubulo villous adenomas in a continent ileostomy after proctocolectomy for familial polyposis. Dig Dis Sci 1982; 27: 553-5.

4 Stryker SJ, Carney JA, Dozois RR. Multiple adenomatous polyps arising in a continent reservoir ileostomy. Int J Color Dis 1987; 2: 43-5.

5 O'Connell PR, Rankin DR, Weiland LH, Kelly KA. Enteric bacteriology, absorption, morphology and emptying after ileal pouch-anal anastomosis. Br J Surg 1986; 73: 909-14. 